\section{(... continued from page 2 )}

ceived and experienced. Its organisation is proceeding quite successfully and the themes to be discussed are especially suitable to the mission of our member schools. My best wishes for the coming summer holidays and to all of you 'arrivederci' in Utrecht in October!

Franco Cavallo, President

\title{
The Board Is Presented
}

We can only continue to emphasize that the Association can only be effective through intense communication and collaboration between members. Members of the Executive Board are expected to facilitate that process. That is precisely the reason that once more their communication details are presented here. They're expecting your phone calls, faxes and electronic mail messages!

\section{Franco Cavallo (President)}

Dept. of Hygiene and Community Medicine University of Torino

Via Santena, 5-bis I-10126 TORINO ITALY

Tel: +39116706556

Fax: +39116706551

E-mail: FCAVALLO@ITOC

SIVM.CSI.IT

Ulrich Laaser (Past President) Institute for Population Research and Social Policy Postfach 100131 D-33501 BIELEFELD GERMANY

Tel: +495211065175

Fax: +49521106 6021

E-mail: u.laaser@post.uni-bielefeld.de

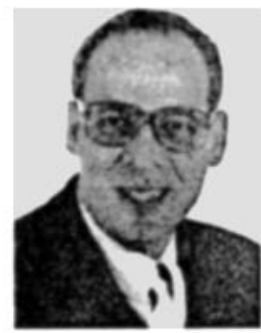

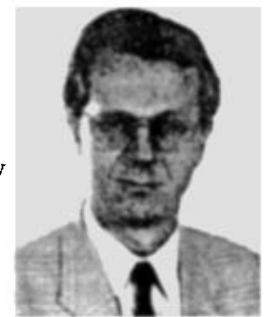

Ferenc Bojan Department of Social Medicine University Medical School of Debrecen P.O. Box 2 H-4012 DEBRECEN HUNGARY Tel: +3652413410

Fax: +3652417424

E-mail:BOJAN@TOT.dote.hu

Lennart Köhler of Public Health

Box 12133

GÖTEBORG SWEDEN

Tel +4631693976

E-mail: LENNART@nhv.se

(... continued on page 294)
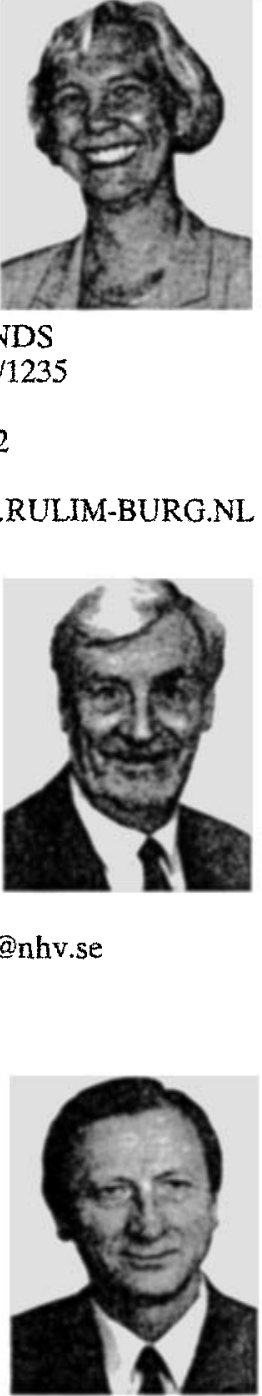

THE NETHERLANDS

Tel: $+31433882222 / 1235$

direct line)

E-mail:

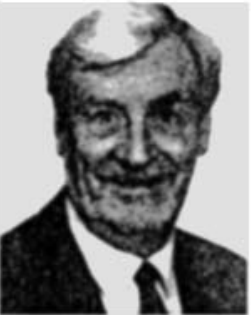

